\title{
Research of Physical Mechanical and Protective Properties of the Lignin Rust Modifier
}

Kulash Syrmanova, Adyl Tuleuov, Zhanat Kaldybekova, Nurjan Botabaev, Sholpan Baijanova, Saule Sakibayeva and Anastassiya Beloborodova

M. Auezov South Kazakhstan State University, Shymkent 160012, Kazakhstan

Received: October 14, 2014 / Accepted: October 24, 2014 / Published: October 25, 2014.

\begin{abstract}
In the given article, the data on preparation of metal surface at anticorrosive protection by paintwork materials are given. Conducted research on water absorption and protective properties of the lignin rust modifier in various hostile environment was carried out. There is shown high anticorrosive efficiency of the developed lignin rust modifiers which will be used for preparation under coloring of steel surfaces with the aim of transforming corrosion products to chemical permanent water insoluble connections which are strongly connected with metal surface.
\end{abstract}

Key words: Metal, anticorrosive protection, rust modifier lignin, paint and varnish covering, water absorption, chemical resistance.

\section{Introduction}

The increase in volume of metal expenses and severe conditions of oil and gas equipment operating makes the problem of increasing the work durability of the equipment work to be one of the most important problems, defining the growth rates and technical and economic efficiency of production and transportation of oil and gas.

The problem of anticorrosive protection of the equipment and constructions of oil refineries (oil refinery) where more than $30 \%$ of metal fund of the country are concentrated, has gained now paramount significance and will require the practical solution in the short term $[1,2]$.

High corrosion loss in the oil-processing and petrochemical industry are caused by considerable outputs and big metal consumption (-32 kg on each ton of recycled oil). The tendencies which have outlined recently and the increase of volume of processing

Corresponding author: Kulash Syrmanova, professor, doctor of technical sciences, research fields: electrochemistry, colloidal chemistry and surfactants. E-mail: kulash.syrmanova@mail.ru. sulphurous and high-sulphurous oil and gas condensates and the need of protection from the corrosion of the equipment and installations for a period of stall and the subsequent preservation for the long period demand a special attention to the issues of fighting with corrosion.

\section{Theoretical Details}

High aggression of operational environments is one of the main reasons for of the oil and gas equipment breakdown, their early destruction. The low work resource of the equipment in hostile environment increases its weight and dimensions, reduces permissible load, needs frequent repairs that raise the costs of production and equipment service, delays the labor productivity growth and increases the product cost [3].

The solution of anticorrosive protection issue of the equipment of oil refinery is impossible without carrying out the detailed analysis of features and the reasons of corrosion defeat of metal of oil and gas pipelines, installations of primary and secondary oil refining on operating in procedural, and differing from 
procedural modes.

One of the perspective directions on the increase of reliability and overall performance of the oil equipment is using of paintwork materials [4-6].

Constant increase of work load, deficiency of technical means and production capabilities for preparation of metal surface under coloring by the mechanical and chemical methods, insufficient output of anticorrosive primers, containing expensive passivating pigments and their ecological harm cause the search of new anticorrosive materials and methods of protection of overcorroded steel, particularly by means of rust modifiers.

According to modern representations, rust modifiers have to provide the stability of phase structure of rusts under paint and varnish covering, the stability of adhesion and cohesion of rust layer and to cause braking of corrosion process, to increase the protective properties of paint and varnish system on the whole [7-13].

Rust modifiers being made now, according to the mechanism of impact on a rust and scale can be divided into four groups [9].

\subsection{PR-Impregnations with Inhibiting Effect}

These are actually traditional paintwork materials (PM) in which compounding one or several inhibitors of corrosion (IC) are added. For the increase of penetration (penetration) the formulas may contain the surface-active substances (SAS).

\subsection{PRK Stabilizers}

The most part of components in PRK is positively charged in relation to iron and therefore activates the electrochemical corrosion.Most PRK components are not stable and under action of insignificant factors change from one state into another, thus altering thus the volume. Such transformations cause the development of internal tension in PRK layer, that leads to its cracking and flaking from the substrate. At last, a number of the PRK components are hygroscopic and function as though as the tank for water and the oxygen dissolved in it. These substances also become the main stimulators, promoting the continuation of corrosion process under a paint and varnish covering.

However, in converters there are components that are stable and not hygroscopic. Long ago the transition phenomenon of iron oxyhydrate (the main components of "fresh" PRK) in these components was known when heating rusty products, as well as at usual temperature, but with low speed. Therefore there has appeared an idea to find such substances which would accelerate this process, and to create rust converters on their basis.

The stabilizers are halo and elargo tannic acids of vegetable origin. These are tannin, the modified lignin, similar to others on a chemical structure of molecules of substance first of all.

\subsection{Rust Converters (RC)}

These are substance mixtures under the influence of which the PRK components turn into inert in relation to corrosion and stable substances in time. Most widely, for this purpose, there used the mixes the main component of which is phosphoric acid (PA) as its salts with iron has passivating action in relation to ferrous metal. This processing creates a phosphatic covering consisting of phosphates of iron on a metal surface.

It demonstrates the electrical properties which do not allow corrosion currents to arise as well as their consequence which is electrochemical corrosion. Along with this, the phosphatic layer causes higher adhesive durability of the paint and varnish covering created on it.

\subsection{Rust Primer Converters (RPC)}

The main feature of GPR is that they represent themselves, as well as RC, water systems. Along with layer formers like water solution or dispersion (emulsion) of polymer there is FC and all additional functional components having in RC. Therefore, under the influence of RPC there are real chemical processes of the PRK transformation. Besides, there is formed 
polymeric covering on the transformed surface at evaporation of water intended at the majority of domestic RPC to carry out function only of soil under a sheeting.

In the given work, there has been conducted research of protective properties of complex systems of chemical resistant paint and varnish coverings in combination with the new modifier of rust: the lignin modifier of rust at testing them in various hostile environment.

Researches were conducted for the purpose of increasing protective properties of modifiers of rust, reducing the expense of scarce components and depreciation of the modifier of rust.

Technical characteristics of properties of the lignin rust modifier in comparison with PRL- are illustrated in Table $1[14,15]$.

Water absorption of a free layer is defined in accordance with 11736-68 all-Union State Standard. Test systems of coverings in hostile environment has been carried out compliance with 9.403-80 all-Union State Standard.

Determination of anticorrosive properties of paint and varnish coverings. Anticorrosive properties of coverings are defined under the conditions, close to operational. As samples metal cores with a diameter of $0.01 \mathrm{~m}$ length $(7-7.5) \times 10^{-2} \mathrm{M}$ the rounded-off end faces are used.

The paintwork materials are put on cores, after cover drying the cores are fixed in the vessels filled with the corrosion environment.

\section{Results and Discussion}

For the needs of national economy a huge number of converters of the rust made of cheap and available raw materials are required.

One of the perspective types of raw materials for development of the new rust converter is the hydrolytic lignin which is large-capacity waste of hydrolytic plants, (the annual emission of which in a dump makes 3.8-4.5 million tonns) and soap stock (waste from oil producing plat) [14].

Water absorption of layer in $80 \mu \mathrm{m}$ in the distilled water at $293{ }^{\circ} \mathrm{K}$ is presented in Fig. 1.

(1) LMR+XC-068; (2) PRL-cx + XC-068;

(3) LMR+XC-765; (4) PRL-cx + XC-765.

Thus, there has been researched water absorption of system of the rust modifier in a complex with paintwork materials on the overcorroded surface (3p.) covered with an even product layer of corrosion in 35-45 $\mu \mathrm{m}$, received as a result of exhibiting the samples within 3 months.

Products of corrosion contain $\gamma-\mathrm{FeOH}(85 \%)$ and $\mathrm{Fe}_{2} \mathrm{O}_{3}(15 \%)$, depending other things being equal from influence of corrosion speed on adhesive interaction with the substrate.

Density of the obtained layer indicates on the fact, that the size of equilibrium water absorption substantially

Table 1 Technical characteristics of lignin properties.

\begin{tabular}{llll}
\hline № & Name of indicators & LMR & PRL \\
\hline 1 & Colour & $\begin{array}{l}\text { Oily liquid of dark brown color } \\
\text { After drying the layer has to be }\end{array}$ & $\begin{array}{l}\text { Oily liquid of dark brown color } \\
\text { After drying the layer has to be } \\
\text { equal, uniform, from light to dark } \\
\text { equal, uniform, from light to dark } \\
\text { brown color }\end{array}$ \\
& Appearance & 12 & 25 \\
3 & $\begin{array}{l}\text { Conditional viscosity at }(20 \pm 0.5)^{\circ} \mathrm{C} \text { on the VZ-4 } \\
\text { viscometer }\end{array}$ & $18-25$ & $20-25$ \\
4 & Mass fraction of nonvolatile substances & 1.98 & - \\
5 & Density at $(20 \pm 2)^{\circ} \mathrm{C}, \mathrm{g} / \mathrm{cm}^{3}$ & $7-14$ & $3-14$ \\
6 & Mass fraction of orto-phosphorus acid, no more & 30 & 30 \\
7 & Degree of grinding, micron, no more & $50-60$ & - \\
8 & Drying time to degree 3 at $(20 \pm 2)^{\circ} \mathrm{C}$, sec., no more & $80-100$ \\
9 & Reformative ability (thickness of the transformed & $80-120$ & \\
\hline
\end{tabular}




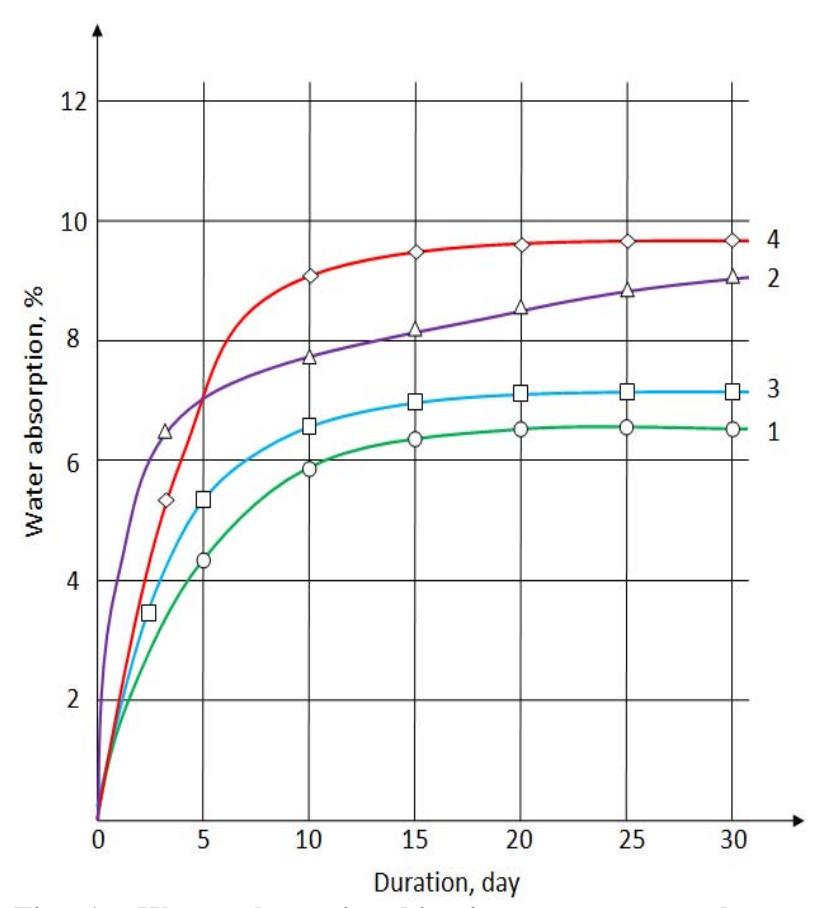

Fig. 1 Water absorption kinetics on a rusty substrate (steel 3).

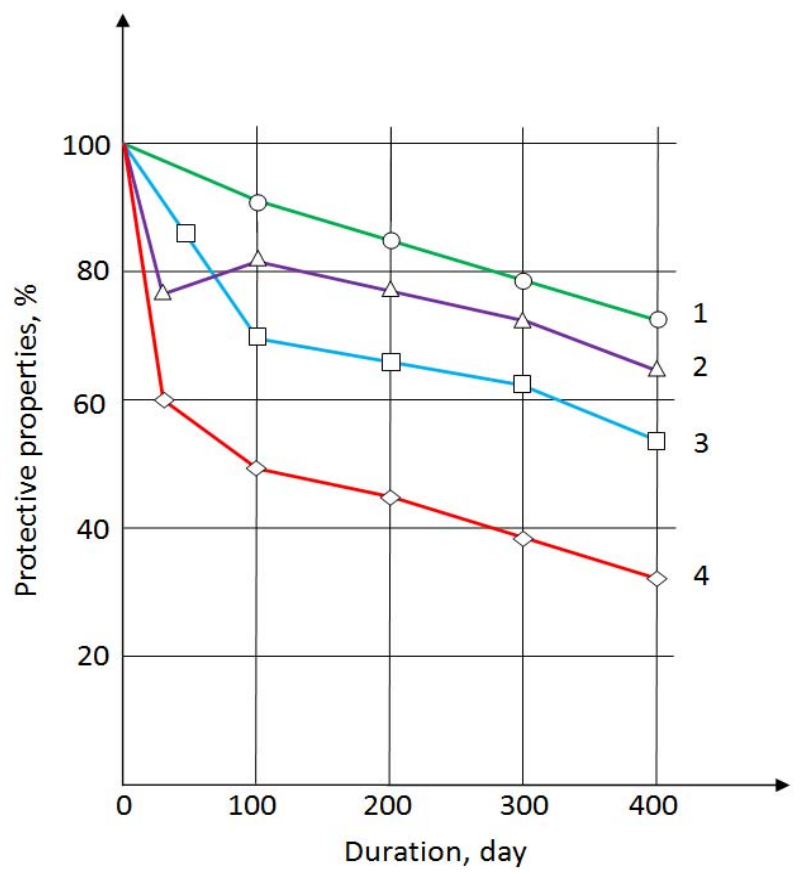

Fig. 2 The dependence of protective properties of the system of chemical resistant coverings with rust modifiers (LMR, PRL) from the time spent in $10 \% \mathrm{H}_{2} \mathrm{SO}_{4}$.

characterizing the properties of the rusts modifier on a over corroded surface for the lignin rust modifier (Curves 1 and 3) is much lower, than at application known in the industry PRL, (Curves 2 and 4). Test of

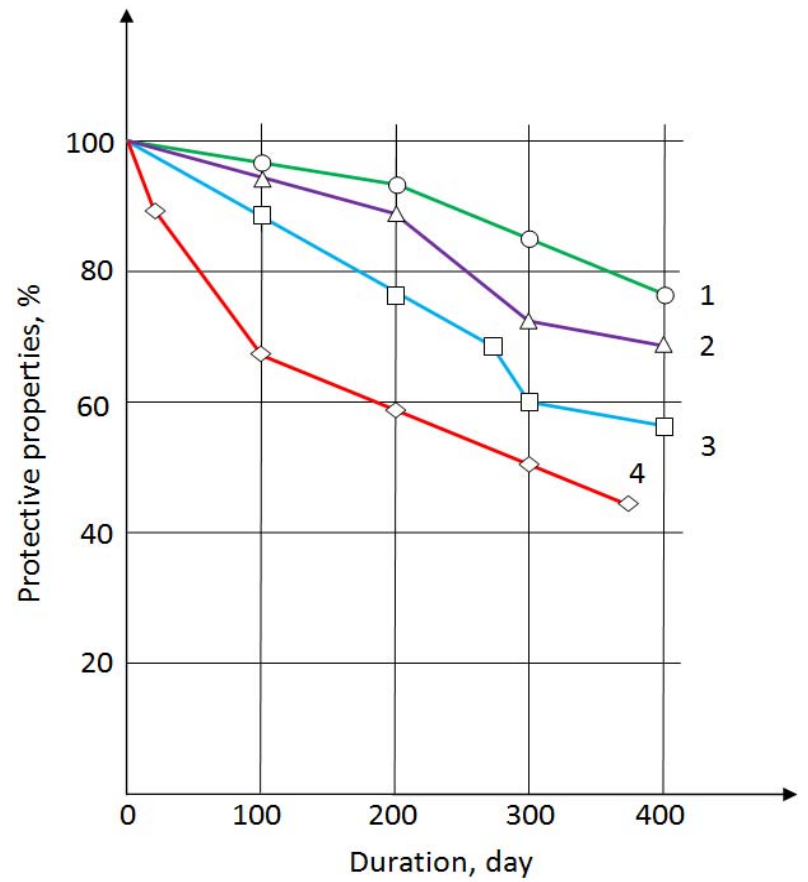

Fig. 3 The dependence of protective properties of the system of chemical resistant coverings with rust modifiers (LMR, PRL) from the time spent in $10 \% \mathrm{NaOH}$.

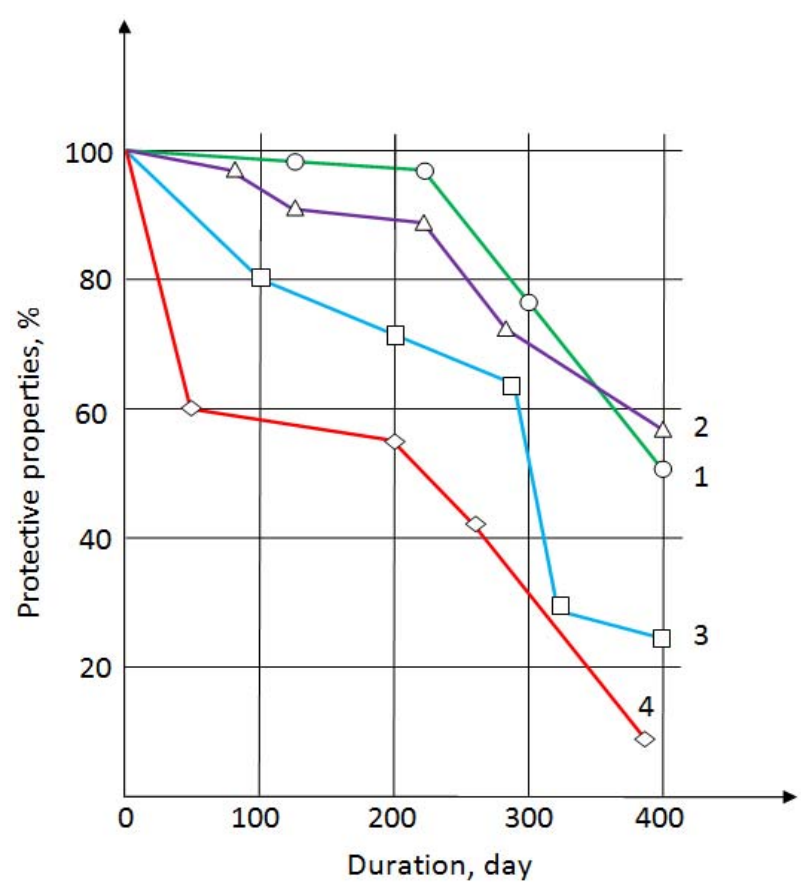

Fig. 4 The dependence of protective properties of the system of chemical resistant coverings with rust modifiers (LMR, PRL) from the time spent in $3 \% \mathrm{NaCl}$.

the lignin rust modifier on chemical firmness was carried out according to 9.403-80 all-Union State Standard by the method full immersion of samples 
solutions of chamois (10 or 25 ache concentration) acids, in $10 \%$ and $20 \% \mathrm{NaOH}$ solution and to $3 \% \mathrm{NaCl}$ solution (Fig. 2).

The generalized assessment of coverings state was carried out according to 9.403-84 all-Union State Standard.

In Fig. 2 as an example, there is presented the graphic data on preservation of protective properties of system of covering HS-068 by the rust modifier (LMR and PRL-) and without them.

From the drawing it is visible that the specified system of LMR + HS-068 preserves its protective properties without any change within 120-200 days.

The test results of system LMR + HS-068 and PRL+ HS-068 have similar features.
The test in $20 \% \mathrm{NaOH}$ solution has showed, that covering of LMR is highly effective. The coverings systems with LMR remain almost without any changes at testing within 300 and more days. At the same time on samples from HS-068 (without rust modifier), after laying directly on a rusty surface, the signs of destruction of coverings are noted after 70-75 days of tests.

The results of visual supervision over condition of coverings with the lignin rust modifier correlate well with the data on protective properties of complex systems of coverings [16]. The final and the most reliable conclusions about effective and protective ability of the lignin a rust modifier can only be made by the tests results of complex systems of paint and varnish coverings with their application (Table 2).

Tabel 2 Physical mechanical properties of the samples protected by the lignin rust modifier and paint and varnish covering.

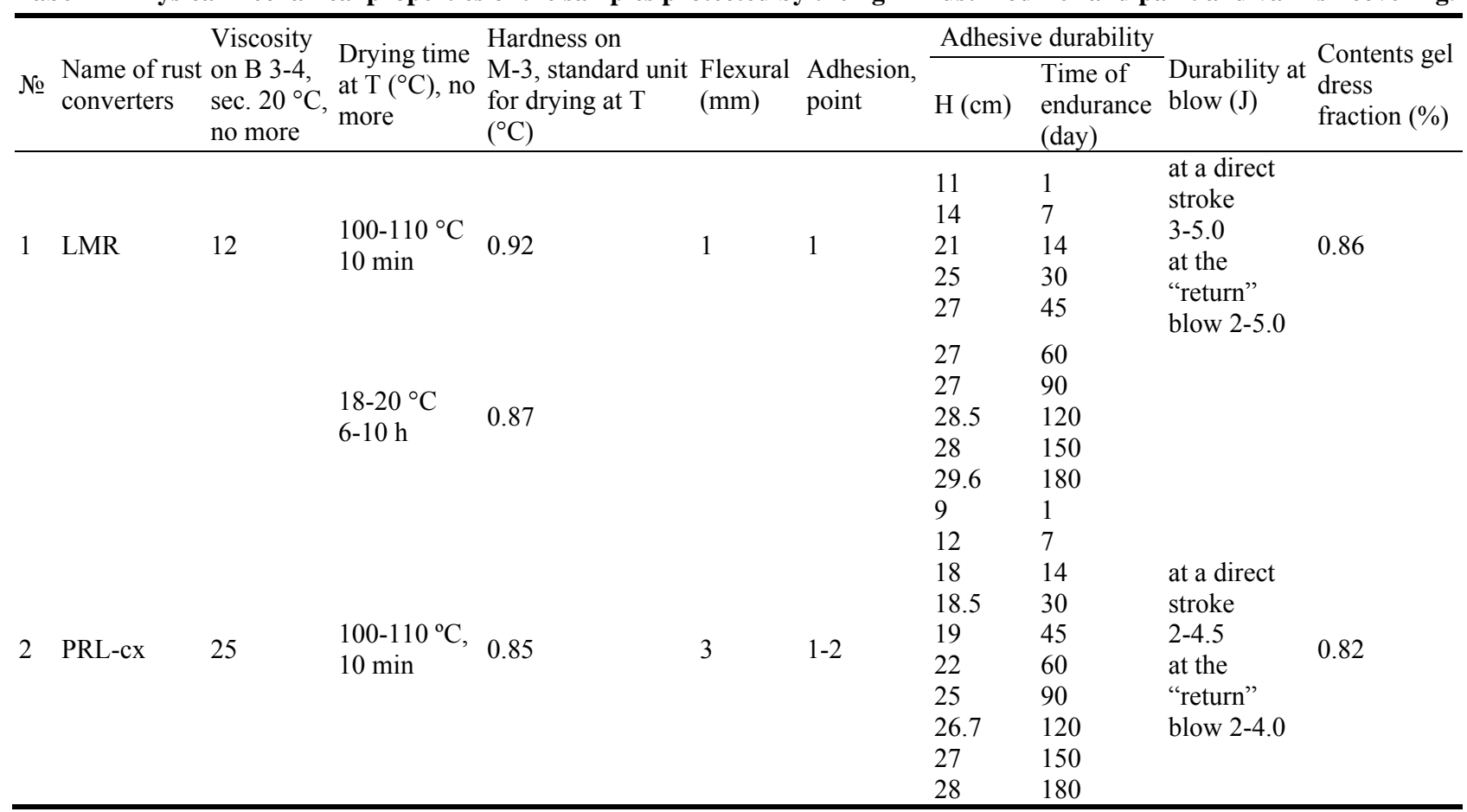

Table 3 Results of the accelerated tests of coverings with the use of rust modifiers.

\begin{tabular}{|c|c|c|c|c|c|c|}
\hline \multirow{3}{*}{$\begin{array}{l}\text { Name of } \\
\text { converters } \\
\text { of a rust }\end{array}$} & \multicolumn{2}{|c|}{ Camera of salt fog (h) } & \multicolumn{2}{|c|}{ Water (h) } & \multicolumn{2}{|c|}{$3 \% \mathrm{NaCl}$ solution $(\mathrm{h})$} \\
\hline & \multicolumn{2}{|c|}{ Destruction } & \multicolumn{2}{|c|}{ Destruction } & \multicolumn{2}{|c|}{ Destruction } \\
\hline & Beginning & End & Beginning & End & Beginning & End \\
\hline LMR & $\begin{array}{l}260 \text {, corrosion } \\
\text { from a cut }\end{array}$ & $\begin{array}{l}1,300, \text { corrosion from a } \\
\text { cut to } 1.5 \mathrm{~mm}\end{array}$ & $\begin{array}{l}2,400, \text { without } \\
\text { change }\end{array}$ & $\begin{array}{l}\text { Tests } \\
\text { proceed }\end{array}$ & $\begin{array}{l}1,200,1 \text { center of small } \\
\text { bubbles }\end{array}$ & $\begin{array}{l}2,200,1 \text { center of } \\
\text { small bubbles } 1\end{array}$ \\
\hline PRL-cx & $\begin{array}{l}260 \text {, corrosion } \\
\text { from a cut }\end{array}$ & $\begin{array}{l}1,300 \text {, corrosion from a } \\
\text { cut } 2 \text { to } 10 \mathrm{~mm}\end{array}$ & $\begin{array}{l}2,400, \text { without } \\
\text { change }\end{array}$ & $\begin{array}{l}\text { Tests } \\
\text { proceed }\end{array}$ & $\begin{array}{l}1,200,3 \text { hearth small } \\
\text { bubbles with a diameter } \\
\text { of } 0.2 \mathrm{~mm}\end{array}$ & $\begin{array}{l}2,200, \text { corrosion } \\
\text { point diameter of } \\
0.5 \mathrm{~mm}\end{array}$ \\
\hline
\end{tabular}


The coverings are characterized by high water and salt resistance reaching more than $1,000 \mathrm{~h}$ (Table 3 ).

\section{Conclusions}

The data obtained in work proves also the fact, that along with the protective properties of the lignin rust modifier, the physical mechanical properties of coverings are investigated as well: the durability at blow: 3-5.0 J, adhesion, 1 point. These indicators are high and points to their high operational qualities in the conditions of casual blows.

In terms of qualitative and operational characteristics, the lignin rust modifier with paint and varnish coverings do not concede in a complex, and according to some indicators, they surpass the industrial rusts that is confirmed by acts of the tests.

Thus, the new lignin rust modifier can be used for preparing under coloring of steel surfaces for the purpose of transforming the products of corrosion to chemical the permanent water insoluble connections which are strongly connected with a surface of metal.

The creation of the composite anticorrosive material "Anticorrosive mixture" allows us to solve a number of following tasks:

- Receiving new composite materials with the best operational properties;

- Saving considerable resources of metal fund of Kazakhstan;

- Rational use of industrial wastes;

- The decrease in the requirement for expensive and scarce anticorrosive priming materials;

- Carrying out the qualified anticorrosive works under hard working conditions, out of covered rooms and at damp surface of buildings.

\section{References}

[1] K.K. Syrmanova, K.Zh. Estekov, Zh.B. Kaldybekova, The solution of regional problems of the anticorrosive chemical equipment and metal construction, in: Conference Problems of Chemical Technology of the Nonorganic, Organic, Silicate and Construction Materials and Preparation of Engineering Shots, 2002, pp. 228-230.

[2] G.S. Kesselman, Economic efficiency of corrosion prevention in oil industry, M. Subsoil, 1988.

[3] M.Z. Assadullin, R.R. Usmanov, R.M. Askarov, A.G. Gareyev, S.M. Fayzulin, Corrosion cracking of the main gas pipelines, Gas Industry (2) (2000).

[4] I.L. Rosenfeld, F.I. Rubenstein, Anticorrosive primers and inhibited paint and varnish coverings, Chemistry, 1980.

[5] N.S. Smirnov, Ya.N. Linkin, Cleanibg steel surfaces, Metallurgy, 1978.

[6] O.I. Steklov, etc. Steel and welded connections testing in the new environment, Metallurgy, 1992.

[7] M.I. Finkelstein, Industrial use of epoxy paintwork materials, Chemistry, 1983.

[8] A.D. Yakovlev. Chtmistry and technology of paint and varnish coverings, L. Chemistry, 1981.

[9] V.A. Voytovich, I.M. Favorskaya, Experience of Industrial Use of a Primer Converter of Rust of VA-01 GISI, Leningrad house of NTP, 1974, p. 32.

[10] Yu.N. Forostyan, E.I. Forostyan, L.V. Protasenko, Reports of the III All-Union Scientific and Technical Seminar, Coloring on Rust-79, Gorky, 1979, pp. 82-83.

[11] F. Deflorian, L. Fedrizzi, P.L. Bonora, Determination of the reactive area of organic coated metals using the breakpoint method, Corrosion 50 (2) (1994) 113-119.

[12] J.A. Nunn, Two-layer coating effective with high temperature liness, Pipe Line Industry 76 (1993) 61-63.

[13] J.R. Scully, S.T. Hensley, Lifetime prediction for organic coatings on steel and a magnesium alloy using electrochemical lmpedance methods, Corrosin 50 (9) (1994) 705-716.

[14] D.A. Abzalova, G.B. Nakipbekova, A.E. Naushabekov, D.V. Klyuzhin, K.K. Syrmanova, New coverings with the low content of volatile organic compounds, Science and Education of South Kazakhstan Magazine, Series Chemistry and Chemical Technology 64-65 (5-6) (2007) 103-105.

[15] K.K. Syrmanova, El-Sayed M. Negim, A.M. Tuleuov, G.Sh. Erkebayeva, The development of composite polymer materials for anti-corrosion protection of oil and gas pipelines, in: International Conferences Application of Efficient \& Renewable Energy Technologies in Low Cost Buildings and Construction, International Conference \& Exhibition. Ankara, Turkey, 2013, pp. 486-490. 